\title{
Using NORAPS for Forecasting Heavy Precipitation with Topographic Forcing
}

\author{
J. Kong \\ M.J. Leach
}

February 1997

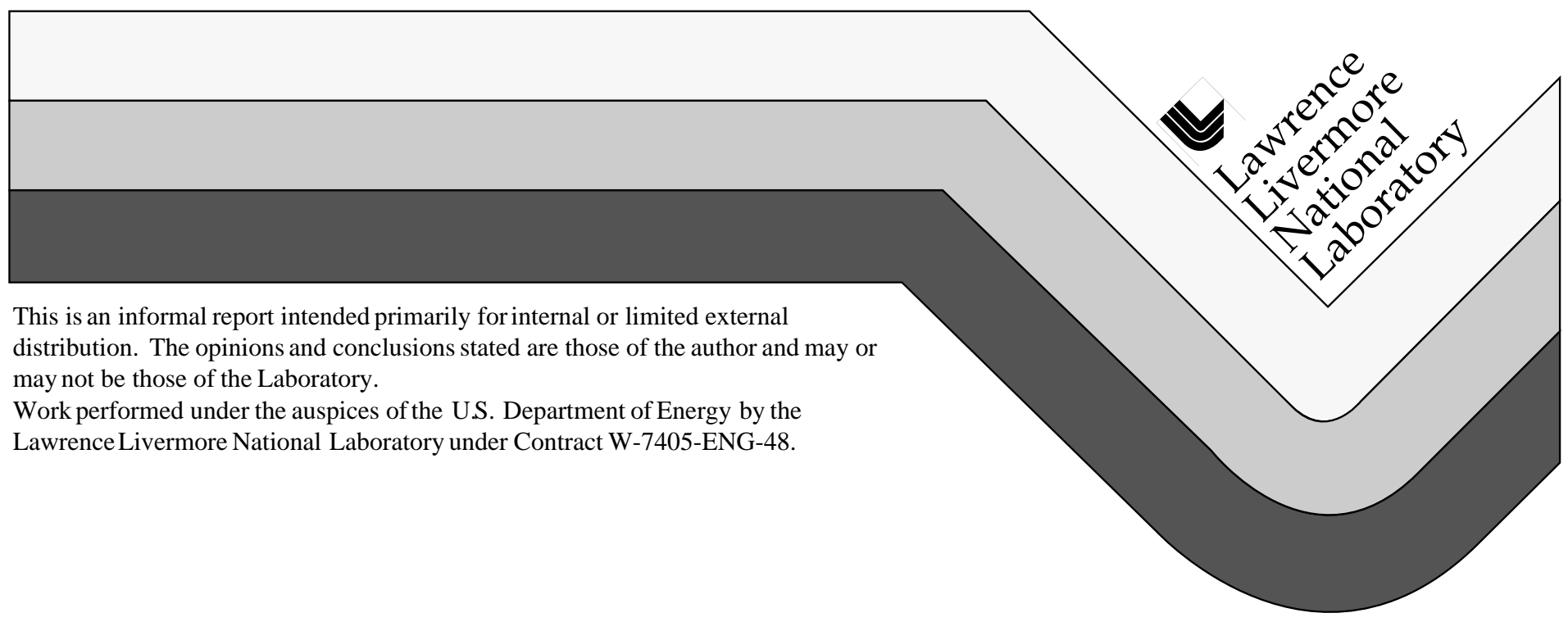




\section{DISCLAIMER}

This document was prepared as an account of work sponsored by an agency of the United States Government. Neither the United States Government nor the University of California nor any of their employees, makes any warranty, express or implied, or assumes any legal liability or responsibility for the accuracy, completeness, or usefulness of any information, apparatus, product, or process disclosed, or represents that its use would not infringe privately owned rights. Reference herein to any specific commercial product, process, or service by trade name, trademark, manufacturer, or otherwise, does not necessarily constitute or imply its endorsement, recommendation, or favoring by the United States Government or the University of California. The views and opinions of authors expressed herein do not necessarily state or reflect those of the United States Government or the University of California, and shall not be used for advertising or product endorsement purposes.

This report has been reproduced directly from the best available copy.

Available to DOE and DOE contractors from the Office of Scientific and Technical Information

P.O. Box 62, Oak Ridge, TN 37831

Prices available from (615) 576-8401, FTS 626-8401

Available to the public from the

National Technical Information Service

U.S. Department of Commerce 5285 Port Royal Rd.,

Springfield, VA 22161 


\title{
Using NORAPS for Forecasting Heavy Precipitation with Topographic Forcing
}

\author{
Jun Kong and Martin J. Leach \\ Atmospheric Science Division \\ Lawrence Livermore National Laboratory \\ Livermore, CA 94551
}

\section{Introduction}

Heavy precipitation events, associated with winter storm systems, frequently produce devastating flooding throughout the state of California. One of the most disastrous floods in recent years occurred in March of 1995. A storm moved through California from March 7 to 11, 1995 causing flooding in a total of 57 counties in California. The storm moved to the northwest coast of California on March 7 and started producing very heavy rainfall on March 8 in northern California. Then the storm moved southward and continuously produced heavy rain as it moved through California. On March 9, a maximum of $177 \mathrm{~mm}$ precipitation fell in northern California. As the storm moved southward, the heavy rainfall struck central and southern California and brought a maximum of $140 \mathrm{~mm}$ precipitation to that area on March 10. In addition to the heavy rain, heavy snow fell in the higher elevations, with snow depths exceeding 12 meters in some locations in the Sierra Nevada mountains, reported by late March (Lott, 1995).

Although such storms have been a research subject for many years, some features of the California storms, such as the slow movement, the mesoscale structure and the orographic effects on the storm movement and structure are not well understood. Consequently, storms such as the March 1995 flood event, are often not well predicted. The purpose of this study is to try to improve our understanding of the underlying physical mechanisms that produce the mesoscale structure and storm movement through the state. A greater understanding of the physical interactions in these storms will ultimately lead to improved precipitation forecasts, including both the spatial and temporal distribution. Improved forecasts benefit society by reducing threat to life and property and to improved water resource management. We have chosen the Navy Operational Regional Atmospheric Prediction System (NORAPS) to simulate the storms and study the dynamics and physics of theses storm systems.

The NORAPS is a triple nested hydrostatic numerical weather prediction model first developed in 1980s at the Naval Research Laboratory. This system has been selected by the National Atmospheric Release Advisory Center (NARAC) and Atmospheric Science Division (ASD) for daily operation as well as scientific research. The model has been used operationally by the Navy 
for several years, and, as with most operational codes, emphasizes speed and robustness of the code. The tradeoff for operational needs has led to simplified physics packages and sub-grid parameterizations. For example, the large scale precipitation is represented by a condensation scheme with immediate rainout. Such schemes most often over predict precipitation amounts.

Although this model serves operational needs well, some deficiencies have also been found. e.g. the model under-predicts the observed diurnal temperature cycle and over-predicts the observed precipitation amounts forecast over the Sierra Nevada. We have added new physics packages to the model in an effort to improve the accuracy of the model and so that we may better understand the physics and dynamics of California winter storms. In the next section, a brief discussion about the physics upgrades will be given. In section 3, a comparison between the original NORAPS and the upgraded version will be given, and in section 4, preliminary results will be resented. Conclusions and summary will be given in section 5 .

\section{Physics Upgrades}

The upgrades, started in June 1996 and finsihed in October, 1996, focus on three physics packages: 1) microphysics, 2) radiation, and 3) soil and surface processes.

\section{a. Microphysics}

The original NORAPS assumes that rain water is produced as soon as the air is saturated. All condensed water falls out although sub-cloud evaporation of raindrops is allowed. The shortcoming of this assumption is that rainfall is produced too soon, especially in high terrain. High terrain forces air to move upward, in turn, the upward motion produces condensation and generates rainfall. This assumption usually produces too much rainfall especially in the mountain areas. We replaced the large scale condensation scheme with a detailed bulk microphysics scheme to simulate the precipitation processes more realistically. In the new scheme, five hydrometer fields are represented: cloud water, rain water, cloud ice, snow and graupel. In sigma coordinates, conservation equations for cloud water $\left(\mathrm{q}_{\mathrm{c}}\right)$ and ice $\left(\mathrm{q}_{\mathrm{i}}\right)$ are of the form

$$
\frac{\partial p_{s} q}{\partial t}=-\frac{\partial p_{s} u q}{\partial x}-\frac{\partial p_{s} v q}{\partial y}-\frac{\partial p_{s} \dot{\sigma} q}{\partial \sigma}+p_{s} \frac{S}{\rho}
$$

Similarly the conservation equations for rain water $\left(\mathrm{q}_{\mathrm{r}}\right)$, snow $\left(\mathrm{q}_{\mathrm{s}}\right)$ and graupel $\left(\mathrm{q}_{\mathrm{g}}\right)$ are

$$
\frac{\partial p_{s} q}{\partial t}=-\frac{\partial p_{s} u q}{\partial x}-\frac{\partial p_{s} v q}{\partial y}-\frac{\partial p_{s} \dot{\sigma} q}{\partial \sigma}+g \frac{\partial \rho V_{T} q}{\partial \sigma}+p_{s} \frac{S}{\rho} .
$$

In the above equations, $S$ represents source-sink terms including conversion between species and are specified as in Rutledge and Hobbs' (1984). $V_{T}$ is the terminal velocity, $\rho$ is air density, $g$ is 
gravitational acceleration and $p_{s}$ is surface pressure. Because the interactions among the hydrometeor fields as well as the evaporation of falling rain are fully considered, this is more realistic than the original assumption.

\section{b. Radiation}

The change in the representation of water created a need for a change in the radiative transfer in the model. In the original model, the optical depth is based solely on the estimated cloudiness, ignoring the differences in optical properties of liquid water and ice. This simplification leads to errors in the computation of radiative transfer due to the differences of the optical properties. Liquid water as well as ice, snow and graupel are computed explicitly in the modified model, enabling us to represent radiative transfer in the atmosphere more realistically. The original radiative transfer scheme in NORAPS was based on a scheme originally developed by Harshvardhan et al. (1987). A version of that scheme that has been modified to account for the interaction of the microphysics with radiative transfer(Chin, 1994) is used to replace the original scheme. Following Chin (1994), the optical depth $(\tau)$, single scattering albedo ( $\tilde{\omega})$ and asymmetry factor $(g)$ are defined as:

$$
\begin{aligned}
& \tau=\tau^{w c}+\tau^{i c}, \\
& \tilde{\omega}=\gamma \tilde{\omega}^{w c}+(1-\gamma) \tilde{\omega}^{i c}, \\
& g=\gamma g^{w c}+(1-\gamma) g^{i c},
\end{aligned}
$$

where

$$
\gamma=\frac{L W P}{L W P+I W P}
$$

$L W P$ is the liquid water path and $I W P$ is ice-phase water path. They are defined as

$$
W P=\int_{0}^{h} w d z
$$

$w$ is liquid or ice-phase water content $\left(\mathrm{g} \mathrm{m}^{-3}\right)$. In addition, the effective emissivity of clouds (Cox, 1976) can be expressed as (Stephens, 1978)

$$
\varepsilon^{\uparrow \downarrow}=1-\exp \left(-a_{0, w c} \uparrow \downarrow \mid W\right)
$$

where $W P\left(\mathrm{~g} \mathrm{~m}^{-2}\right)$ is water path, and $a_{0}$ defines a mass absorption coefficient for total infrared flux. For liquid water

$$
a_{0}{ }^{\downarrow}=0.158 \quad \mathrm{~m}^{2} \mathrm{~g}^{-1}, \quad{a_{0}}^{\uparrow}=0.130 \quad \mathrm{~m}^{2} \mathrm{~g}^{-1}
$$

and for ice phase water (Starr and Cox, 1985),

$$
a_{0}{ }^{\downarrow}=0.050 \quad m^{2} g^{-1}, \quad a_{0}{ }^{\uparrow}=0.060 \mathrm{~m}^{2} \mathrm{~g}^{-1} .
$$

The effective emissivity of mixed-phase clouds is expressed as (Chin, 1994)

$$
\varepsilon^{\uparrow \downarrow}=1-\exp \left(-a_{0, w c}{ }^{\uparrow \downarrow} L W P-a_{0, i c}{ }^{\uparrow \downarrow} I W P\right) .
$$


In addition to the liquid and ice-phase hydrometeors, aerosol is also considered in the new radiation scheme to ease future development.

Results from our radiation model were compared to results from a more detailed radiation model (Fu and Liou, 1993) with the same atmospheric conditions. The differences between the results from the two models were small.

\section{c. Soil Model}

The surface energy balance includes shortwave and longwave radiation, turbulent sensible and latent heat fluxes, and sensible heat and moisture transfer in the near surface soil layers. The energy balance at the atmosphere/earth interface affects the boundary layer processes, especially the turbulence intensity, with feedback to the structure of the entire troposphere. The proper representation of soil moisture and temperature affects the other terms in the surface energy balance, specifically the partitioning of energy between the sensible and latent turbulent heat fluxes. Soil temperature and ground wetness were represented by climatological means in the original NORAPS. Averaging is an inherent smoothing process, and using climatological averages leads to under predicting the extremes of the wet winter and dry summer seasons in the southwest United States. This problem can be solved by a soil model where both soil temperature and moisture are prognostic . A two layer soil/ground surface submodel, the Coupled Atmosphere Plant Snow (CAPS) model has been added to NORAPS. CAPS, originally developed at Oregon State University (Mahrt and Pan, 1984; Ek and Mahrt, 1991; Kim et al., 1994), predicts the evolution of soil water content, canopy water content and soil temperature. So, in the winter time, soil moisture is enhanced by rainfall and in the summer time, the moisture is reduced. Also, the role of vegetation in evaporation and rain water runoff is fully considered in the soil model.

\section{Comparisons Between the Original NORAPS and the Upgraded Version}

These additions to NORAPS are expected to improve simulations using NORAPS at the cost of increased computer time. To document the improvement, we simulated the March 8, 1995 storm with both versions and compare to the observed data. The simulations were for 72 hours, initialized at 0000 GMT on 8 March. There were 91x91 horizontal grid points, with $\Delta x=\Delta y=$ $13.5 \mathrm{~km}(1215 \times 1215 \mathrm{~km})$. The vertical $\sigma_{\mathrm{p}}$ grid $^{1}$ has greater resolution near the earth's surface, with coarser resolution in the middle and upper troposphere and lower stratosphere. The center of

\footnotetext{
${ }^{1} \sigma_{\mathrm{p}}=\mathrm{P} / \mathrm{P}_{\mathrm{S}}$, where $\mathrm{P}_{\mathrm{S}}$ is the surface pressure. In the simulations described in the text, the sigma levels are defined at $.02, .05, .08, .115, .155, .195, .235, .275, .315, .355, .395, .435, .475, .525, .575$, $.625, .675, .725, .765, .805, .835, .865, .885, .905, .925, .940, .950, .960, .970, .978, .984, .988, .992$, $.995, .998,1.000$.
} 
the grid is $37.75 \mathrm{~N}$ and $236.78 \mathrm{~W}$, near Oakland CA. The northern boundary of the domain is in the southern portion of Oregon and the southern boundary is in Baja California. The eastern boundary is very close to the border between Nevada of Utah.

The initial data is obtained from ETA model analysis, available from the National Centers for Environmental Prediction. Currently, both ETA and the Navy Operational Global Atmospheric Prediction System (NOGAPS) data are available. The ETA model has finer resolution and it is chosen for the initial data used here. ETA analysis data is also used as boundary conditions for the NORAPS forecast.

The comparisons between the two NORAPS versions and observations are focused on temperature, precipitation, cloud distribution and radiation as well as the wind field. Because all the observed surface pressure data have been adjusted to sea level, no attempts have been made to compare the model forecast pressure with the observations. The humidity field is not considered due to insufficient data.

\section{a. Temperature}

The temperature in the lowest layer of the model is compared with the observations since the observations are all surface data . Although this comparison has obvious limitations, it is helpful in assessing the influence from both the new soil model and radiative transfer scheme. Both the soil model and the new radiative transfer module affect the surface energy balance, and therefore the ground temperature and moisture, which in turn affects the air temperature near the surface.

Figure 1 shows the surface temperature distribution after 48 hour forecast using original NORAPS. The same temperature distribution but from modified NORAPS is displayed in Fig. 2. No significant difference can be found between these two figures. To find out which forecast is closer to the observed data, a detailed comparison is made. Nine stations in California are chosen for comparison. Two of the stations, Sacramento and Bakersfield, are located in the Central Valley, three stations, Oakland, Salinas, and Las Tablas, are in the coastal zone of California, and four stations, Grasshopper, South Lake, Mohave River Sink, and Warm Springs, are in the mountain area surrounding the Central Valley. The average differences over these 9 stations between the original and modified NORAPS and observations are displayed in Fig. 3. Due to insufficient observational data, only the first 48 hour simulated temperature is compared with the observation. The absolute difference between the modified NORAPS and observations is shown in Panel A. Similarly, the absolute difference between the original NORAPS and the observations is shown in Panel B. The model tends to produce the largest error during the daytime. The difference between Panel A and B is shown in Panel C. It indicates that the modified NORAPS has 
smaller error during the night time but larger error during the day Both the modified and original NORAPS have the same error character, suggesting that the error may be caused by the computation of sensible and latent heat near the surface. as well as the temperature advection.

\section{b. Precipitation}

The differences in the precipitation forecasts between the original and modified model are small through the first twenty-four hours of simulation. However, the differences are much larger in the forecast from hour 24 to 48, when the storm made its major impact on California. Observations (Fig. 4) indicate that, from GMT 0000 March 9 to GMT 0000 March 10, 1995, about $60 \mathrm{~mm}$ precipitation was produced in both northern and southern California. The forecast value from the original model (Fig. 5) in the central valley is still close to observed but on the Sierra Nevada, the accumulated rainfall reaches as much as $280 \mathrm{~mm}$. Considering that the temperature over the higher mountain elevations is below freezing, possible snow fall amounts could be up to $2.8 \mathrm{~m}$. This is over predicted. The output from the modified model (Fig. 6) is more reasonable. Over the mountain area, the maximum precipitation in 24 hours is $150 \mathrm{~mm}$, approximately $54 \%$ of the precipitation in the original model.

The major reason that the rainfall over Sierra Nevada is much less in the new version of NORAPS is due to the cloud microphysical processes. In the original version, as mentioned above, all the condensed water vapor is transformed into rainwater and all the rainwater is accumulated at the ground. In reality, cloud droplets or ice crystals form and grow through the microphysical processes such as accretion, collection and deposition. Eventually, as the hydrometeors get large, they fall as either raindrops or snow flakes. The growth processes and the fall of the hydrometeors to the ground take time. This is especially true for snow, where the terminal velocity of the flakes is small relative to raindrops, with the implication that water is delivered to the ground at a slower rate when temperatures are below freezing. Also, water and ice, in the form of cloud droplets and crystals are left aloft and advected out of the region. All of these processes account for the smaller, but more realistic, forecasts of precipitation amounts over the Sierra.

\section{c. Cloud and radiative heating}

Since microphysical processes are included in the modified model, this provides the opportunity to compare the model clouds with the observation. Figure 7 is the infrared image at 00Z March 10, 1995 from a GOES satellite, showing the storm system over the western United States. The cloud band in the system extends from Washington, through Oregon, Nevada and California to the ocean. The model domain includes all of California and the ocean to the west, 
extends to the Oregon border to the north and into western Nevada to the east. Figure 8 shows the cloud generated by the model. The cloud pattern agrees well with the satellite image, correcting for the domain differences. It is important to simulate the cloud distribution correctly because it can improve the forecast of rainfall locations. Also, it is helpful in radiation transfer computation.

\section{Some Preliminary Results}

The model simulations reveal several features interesting that contributed to the flooding during the March 1995 storm. These include a strong southwesterly wind $\left(V_{\text {MAX }}=17 \mathrm{~m} \mathrm{~s}^{-1}\right)$ area off the central and southern California coast, strong warm air advection (WAA) in this area and orographic influences (Fig. 9). The strong southwesterly wind close to the coast transported large amounts of water vapor from the warm, tropical Pacific. The horizontal water vapor distribution at $950 \mathrm{hPa}$ is shown in Figure 10. Notice how well the moisture tongue coincides with the maximum wind zone. The box over the central California coast defines the position of a nested grid.

WAA was enhanced at low levels as the California orography affected the low level flow in general and the strong wind off the coast in particular. The temperature advection was very weak on March 8, the beginning of the simulation (Not shown). The low level winds ahead of the front shifted directions from southwesterly to more southerly and southeasterly as the storm approached the coast. The blocking influence of the coastline and topography created veering winds, enhancing the WAA. The deflection of the winds by the coastal mountains and the enhanced WAA is seen clearly in Figure 9.

Vorticity and divergence at hour 40, and the accumulated precipitation at hour 48 for the inner grid defined in Figure 10 are shown in Figure 11, along with the topography. The vorticity and divergence are from sigma level $=.95$, or about $950 \mathrm{hPa}$, where the large scale flow is from the southwest. The relationship of precipitation to the vorticity and divergence patterns to the east of Monterey Bay is clear. The precipitation bands line up with centers of positive vorticity and areas of convergence. The vorticity is generated by the winds interacting with the coastal mountains south of the bay. At this level, the flow goes around these mountains, rather than over it, generating lee vortices. Convergence associated with the vortices creates upward vertical motion and precipitation. Later in the simulation (not shown), the flow speed was greater (i.e. higher Froude number) and the air traveled over the mountain rather than being forced around it. The lee vortices were not formed and precipitation ceased.

\section{Conclusions}


NORAPS has been modified by replacing some of the physics modules in the original model with more detailed physics packages. Specifically, three packages have been replaced. A detailed bulk microphysics scheme replaced the large scale condensation scheme, the radiative transfer scheme was modified to account for the presence of cloud water and ice, and a full soil model was added to replace using climatological means for transport and storage of soil heat and moisture. We documented these changes and presented preliminary results from the model simulations.

The new model improves the precipitation forecasts dramatically. Precipitation amounts are more realistic in the new model, especially in high terrain. The new cloud forecasts agree well with satellite imagery. The improvements in the low level temperature forecasts are less convincing, with large errors from the new model in daytime. We need further analysis of the simulations to find the cause of these errors, but we suspect the linkage between the soil model and the surface sensible and latent heat fluxes.

\section{References}

Bluestein, H. B., 1986: Fronts and jet streaks: A theoretical perspective. Mesoscale Meteorology and Forecasting, edit P. S. Ray, AMS, Boston, 793 pp.

Bradley M. M., H.-N. Chin, M. J. Leach, J. R. Albritton, J. Kong and D. L. Ermak, 1997: Final report for LDRD project 94-ERD-037: Multi-scale atmospheric simulation system, LLNL, UCRL-ID-126222

Chin, H.-N. S., 1994: The impact of the ice phase and radiation on a midlatitude squall line. $J$. Atmos. Sci., 51, 3320-3343.

Cox, S. K., 1976: Observation of cloud infrared effective emissivity. J. Atmos. Sci., 33, 287-289.

Ek, M. and L. Mahrt, 1991, OSU 1-D PBL model User's Guide, Dept. of Atmos. Sci., Oregon State University, Corvallis, Oregon, 118 pp.

$\mathrm{Fu}, \mathrm{Q}$ and K.-N. Liou, 1993: Parameterization of the radiative properties of cirrus clouds. J. Atmos. Sci., 50, 2008-2025.

Harshvardhan R. D., D. A. Randall and T. G. Gorsetti, 1987: A fast radiation parameterization for atmospheric circulation models, J. Geophys. Res., 92, 1009-1016.

Houze, R. A., 1993: Cloud Dynamics, Academic Press Inc. San Diego, 573 pp.

Kim, J., M. Ek and B.L.Lee, 1994: A long term simulation of surface fluxes and soil moisture, Proceedings of the 6th Conference on Climate Variations, 23-28 January 1994, Nashville, Tennessee.

Lott, N., 1995: January and March 1995: A California cloudburst. National Climatic Data Center Research Customer Service Group, Technical report 95-01, 12 pp. 
Mahrt, L. and H.-L. Pan, 1984: A two-layer model of soil hydrology. Bound. Layer Met., 29, 120.

Rutledge, S. A. and P.V. Hobbs, 1984: The mesoscale and microscale structure and organization of clouds and precipitation in midlatitude cyclones. XII: a diagnostic modeling study of precipitation development in narrow cloud-frontal rainbands. J. Atmos. Sci., 41, 2949-2972.

Starr, D. O'C. and S. K. Cox, 1985: Cirrus clouds. Part I: a cirrus cloud model. J. Atmos. Sci., 42, 2663-2681.

Stephens, G. L., 1978: Radiation profiles in extended water clouds. II: parameterization schemes. $J$. of Atmos. Sci., 35, 2123-2132.

\section{Captions}

Fig. 1 Surface temperature distribution after 48 hour forecast using original NORAPS.

Fig. 2 As same as Fig. 1 but using modified NORAPS.

Fig. 3 Average temperature forecast error over nine stations in California from the modified (panel A) and the original (panel B) NORAPS. Panel C shows the difference between panel A and B. It shows that the modified model has smaller error during the evening but larger error in the daytime.

Fig. 4 Observed 24 four precipitation on March 9, 1995.

Fig. 5 Predicted precipitation on March 9, 1995 by the original NORAPS (unit: inch).

Fig. 6 Predicted precipitation on March 9, 1995 by the modified NORAPS (unit: inch).

Fig. 7 Infrared image at 00Z March 10, 1995 from a GOES satellite.

Fig 8. Cloud pattern generated by the microphysical processes in the modified NORAPS.

Fig. 9 Wind distribution in the low level $(950 \mathrm{hPa})$. A strong wind zone $\left(\mathrm{V}_{\mathrm{MAX}}=17 \mathrm{~m} / \mathrm{s}\right)$ can be seen from southwest of the model domain to the central coast area of California. This strong wind transport abundant water vapor to central California. 
Fig. 10 The distribution of low level mixing ration of water vapor after 48 hours simulation. The square box over the central California coast indicates the location of an inner grid.

Fig. 11 Vorticity (upper left panel) and divergence (lower left panel) at hour 40 at level $\sigma=.95$, the 24 hour accumulated precipitation at hour 48 (upper right panel) and the topography (lower right). 


$$
\begin{gathered}
\text { NORAPS grid } 1,91 \times 91 \times 36 \quad 13.50 \mathrm{~km} \\
\text { ht sfc air temp }
\end{gathered}
$$

$48 \mathrm{~h} 0 \mathrm{~m}$ forecast valid at 1995031000 from 1995030800

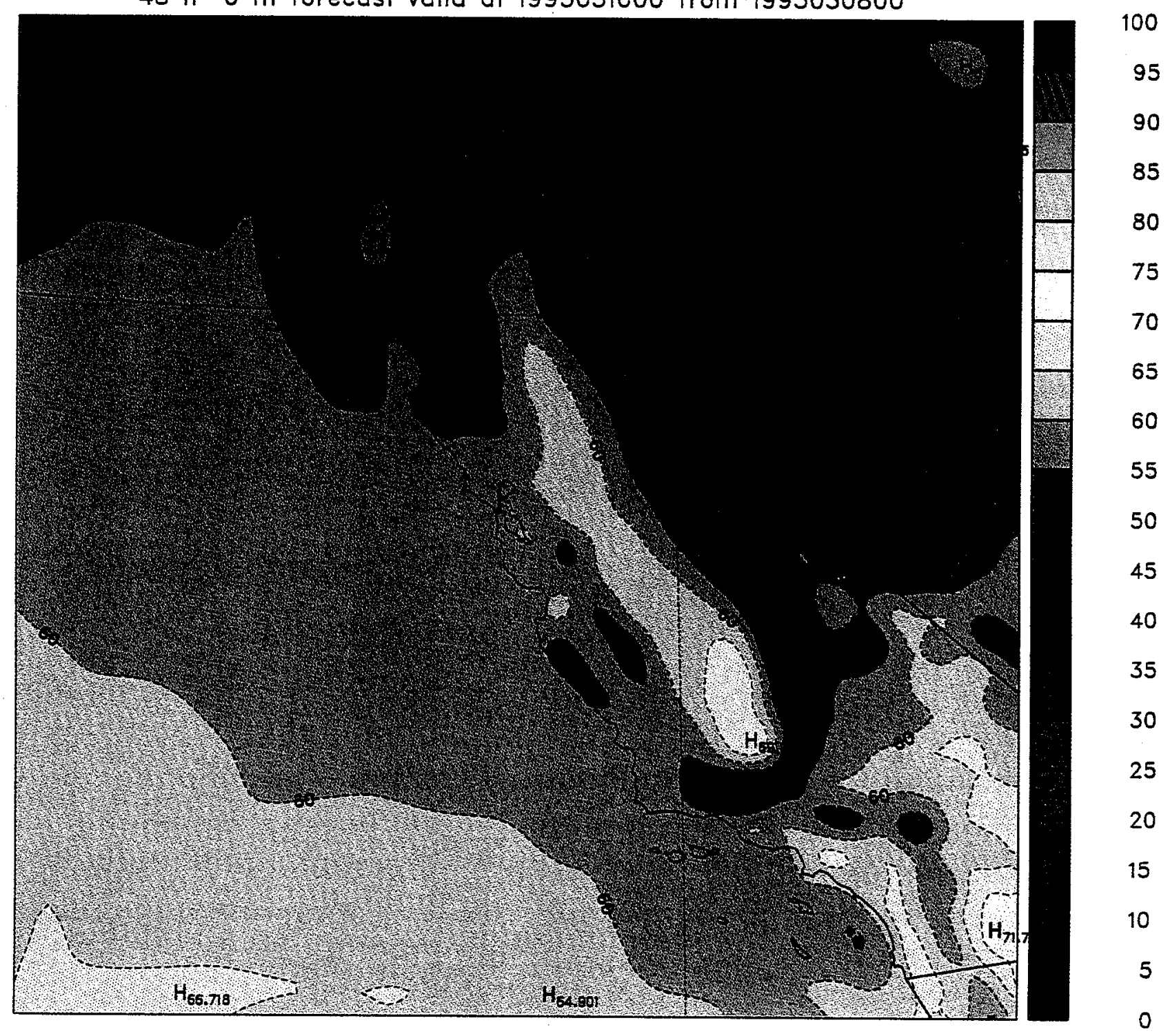



NORAPS grid 1, $91 \times 91 \times 36 \quad 13.50 \mathrm{~km}$
ht sfc air temp

$48 \mathrm{~h} 0 \mathrm{~m}$ forecast valid at 1995031000 from 1995030800

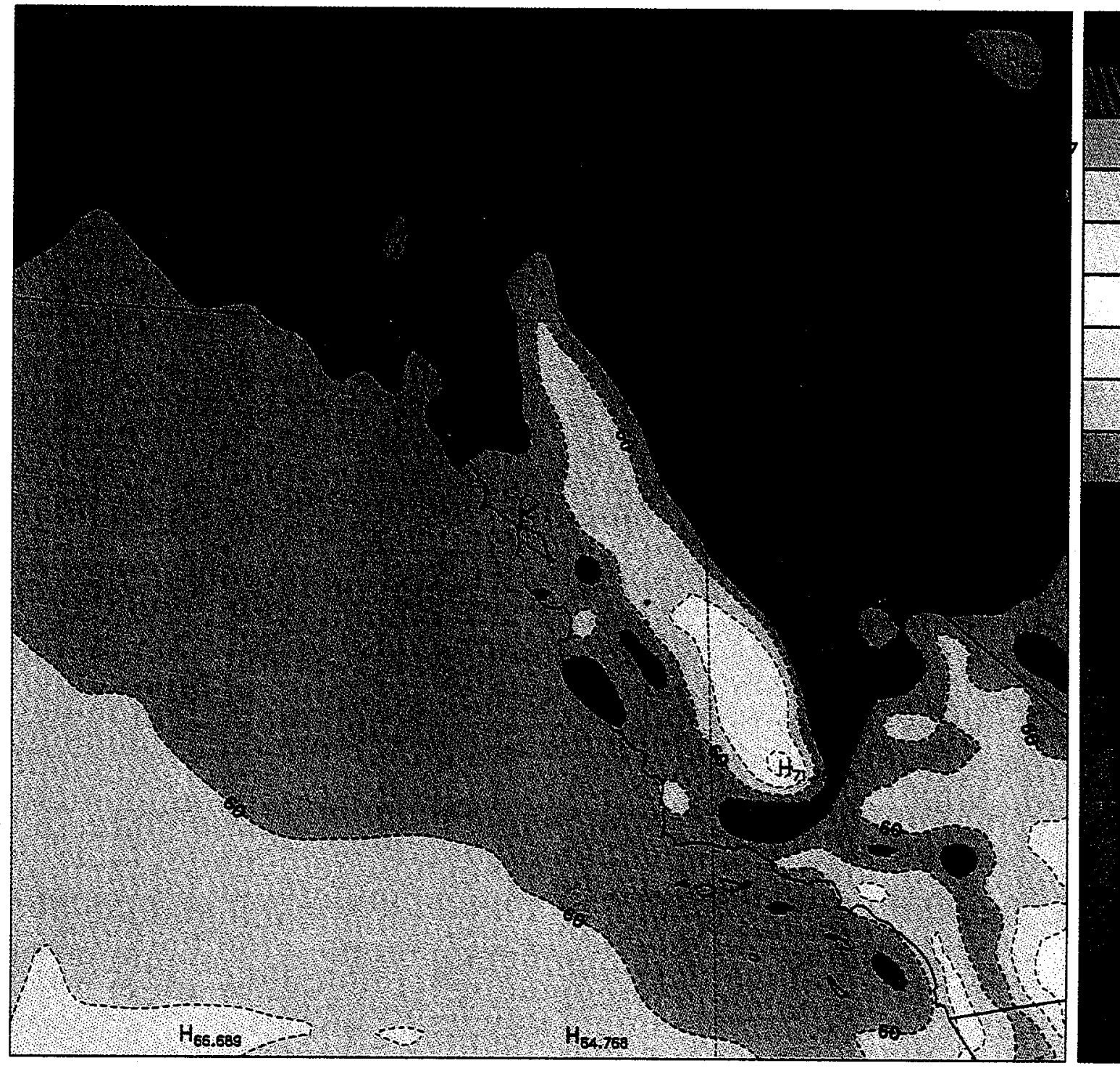



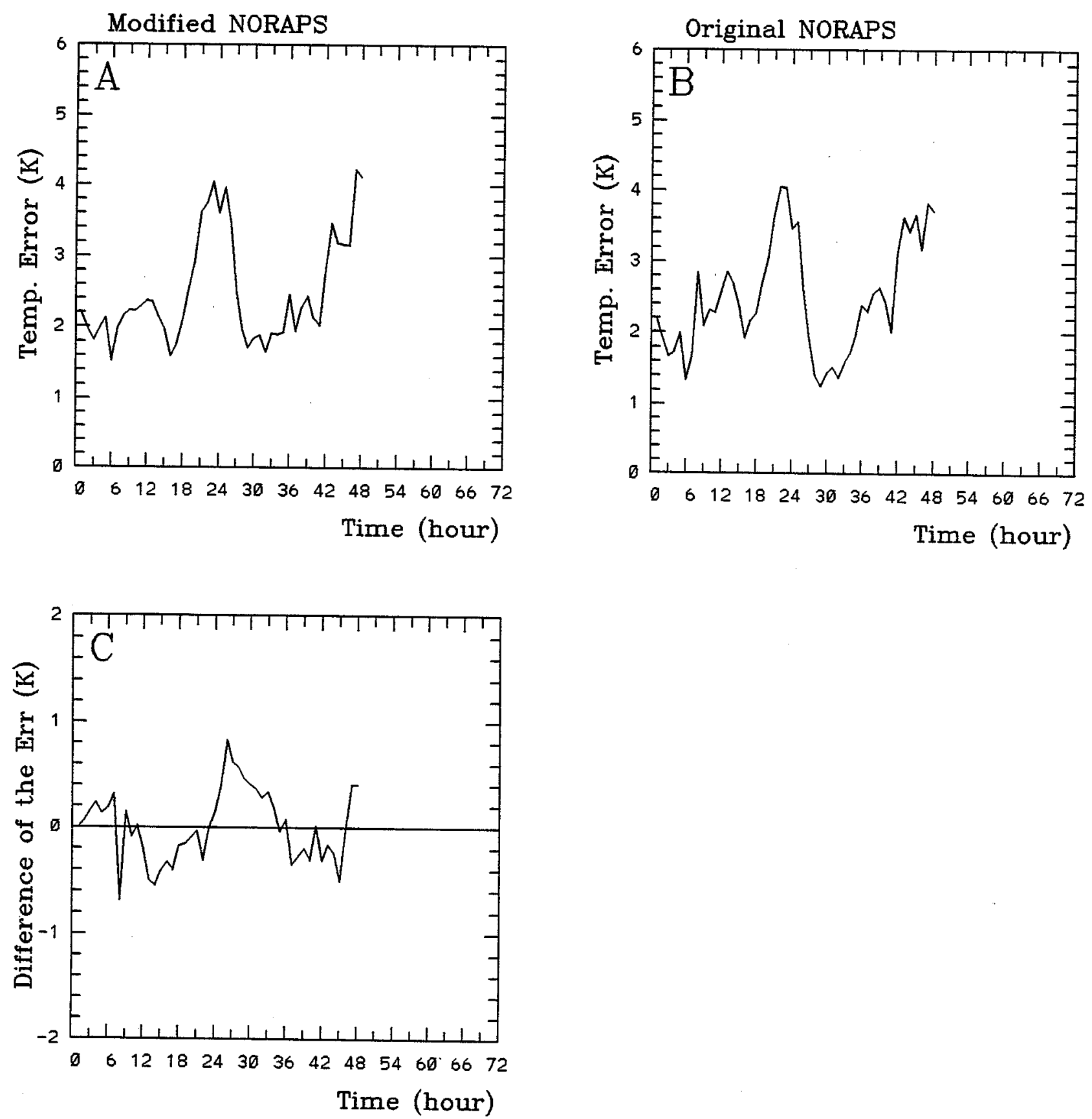

$F \cdot g$ 
$24 \mathrm{hr}$ acc precip $10 / 0$

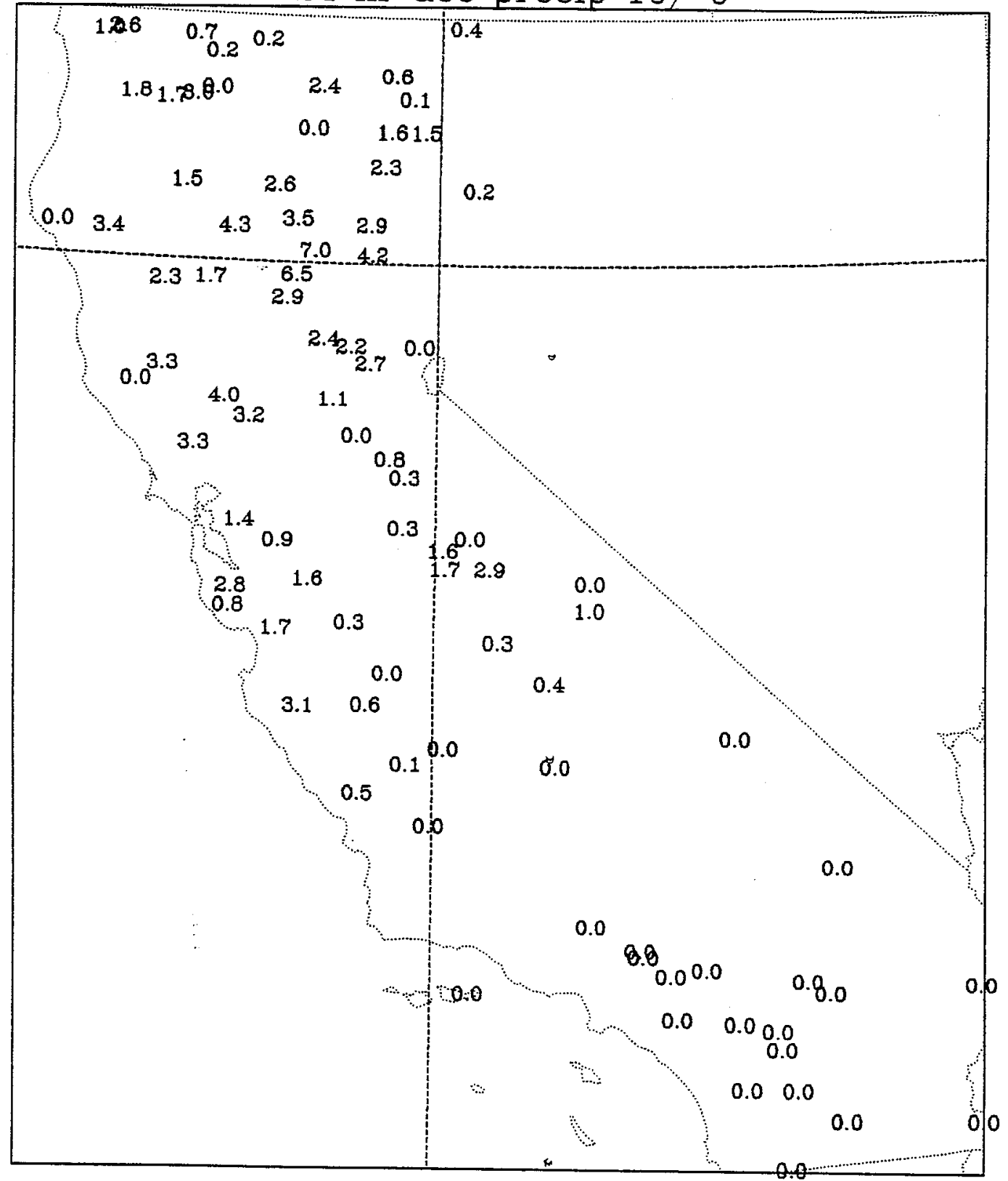

Fig. 4 


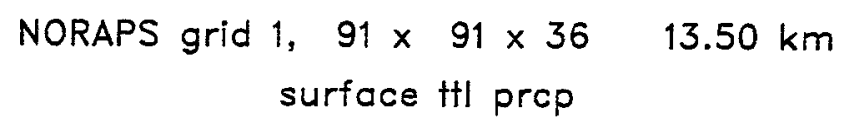

$48 \mathrm{~h} \mathrm{O}$ m forecast valid at 1995031000 from 1995030800

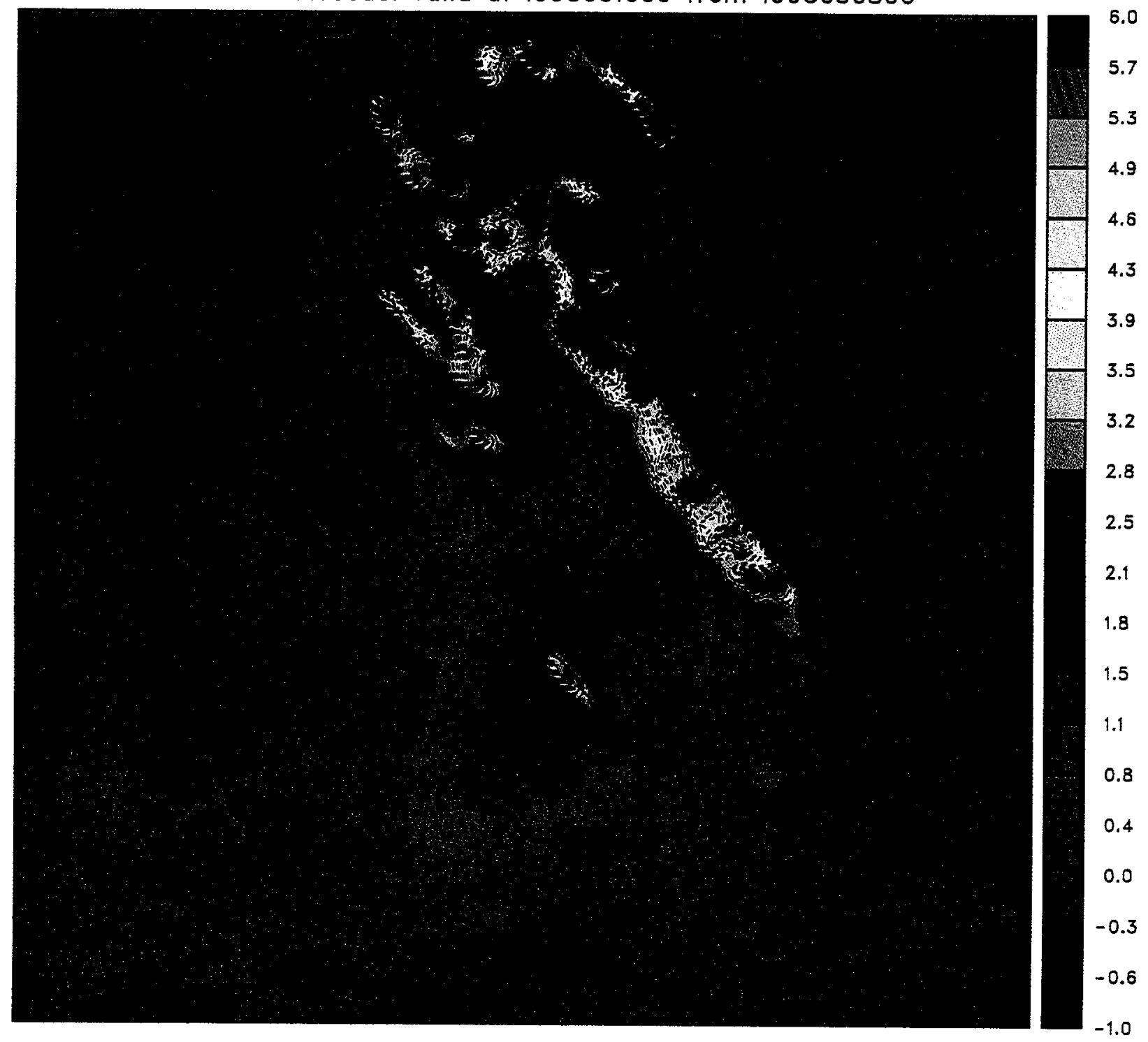


NORAPS grid $1,91 \times 91 \times 36 \quad 13.50 \mathrm{~km}$

surface ttl prep

$48 \mathrm{~h} 0 \mathrm{~m}$ forecast valid at 1995031000 from 1995030800

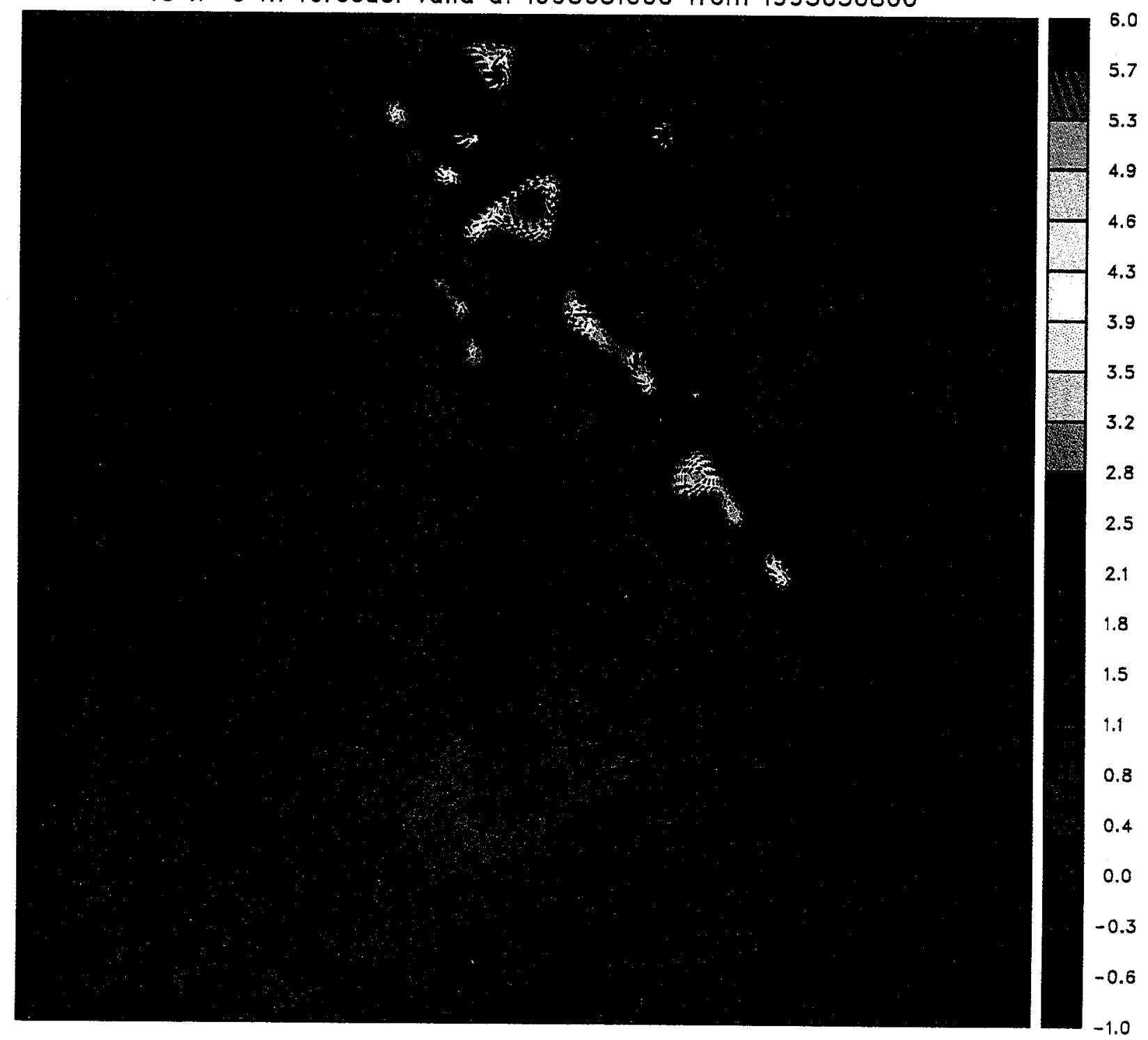


$=$
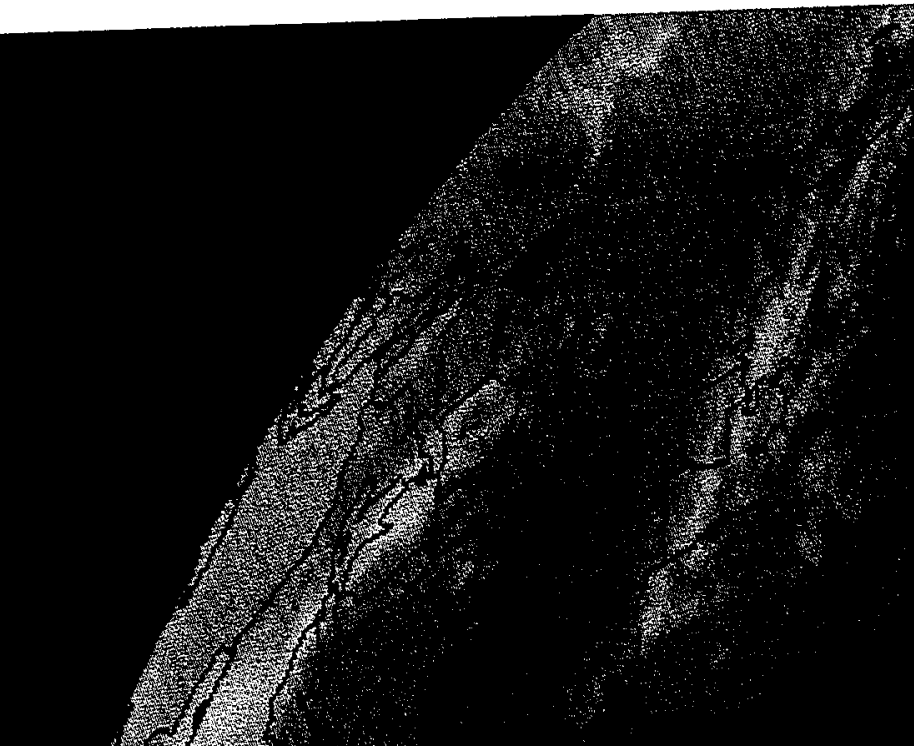

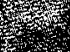

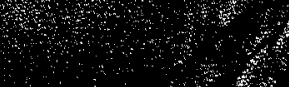

2.

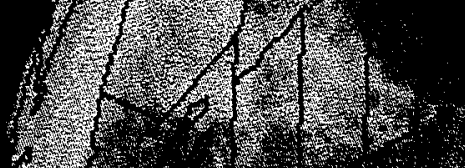

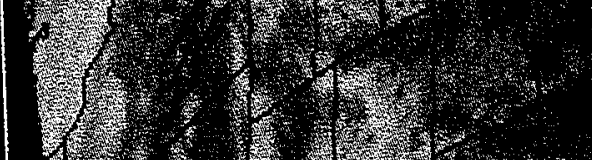

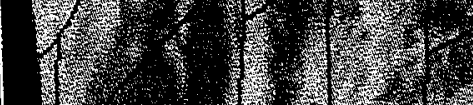

(3)

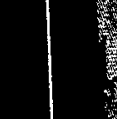

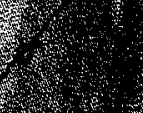

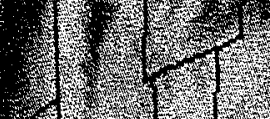

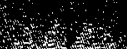

3

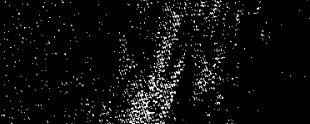

1.

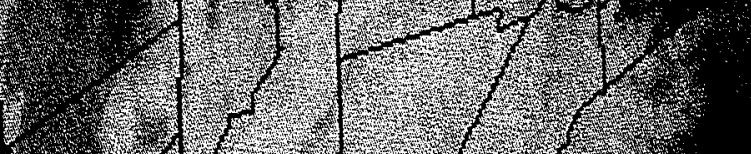

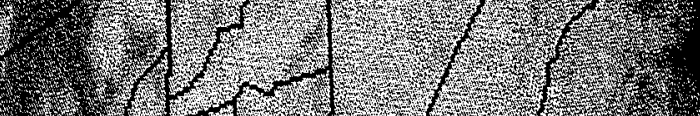
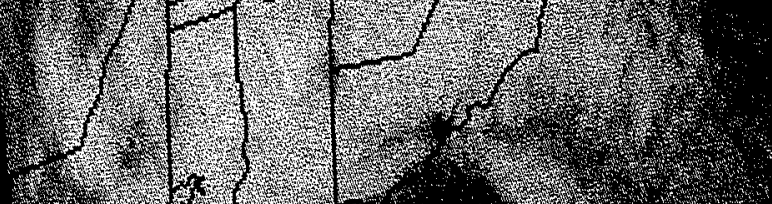

1.2.

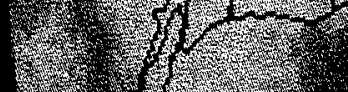

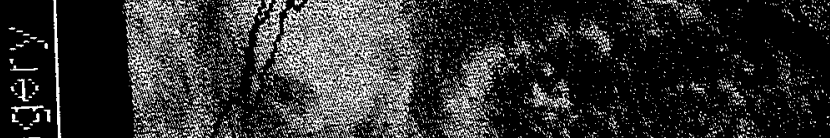

trat

$1 \quad$ (2)

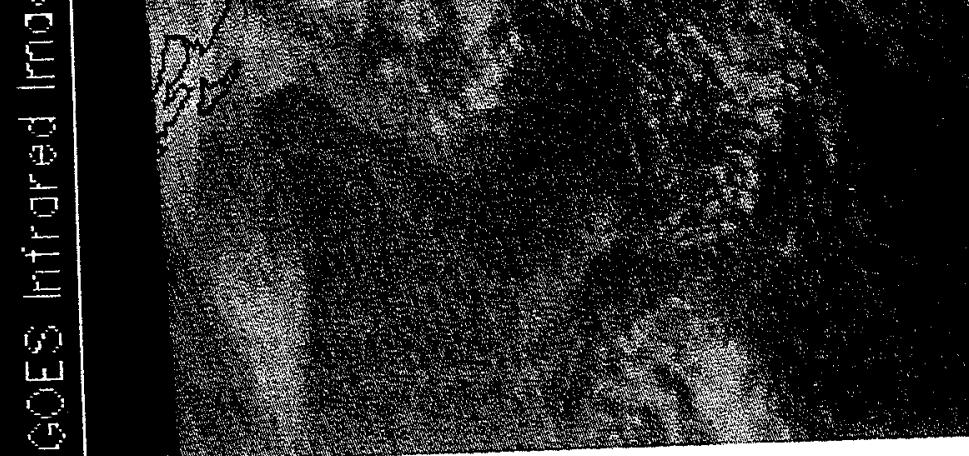




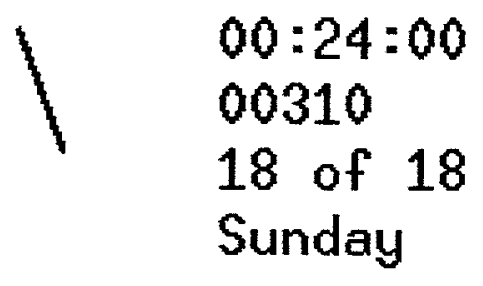

N

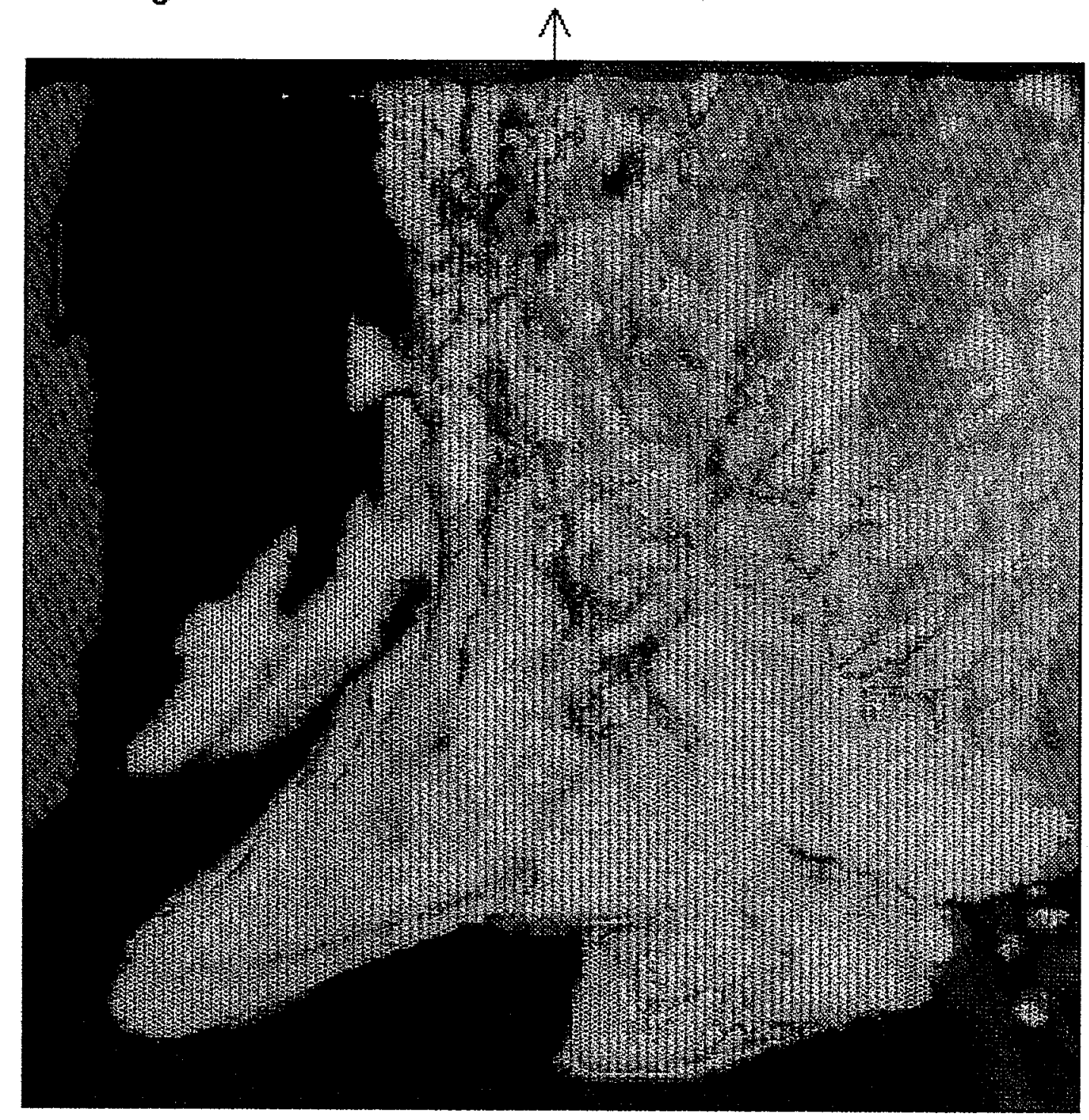

Vis5L 


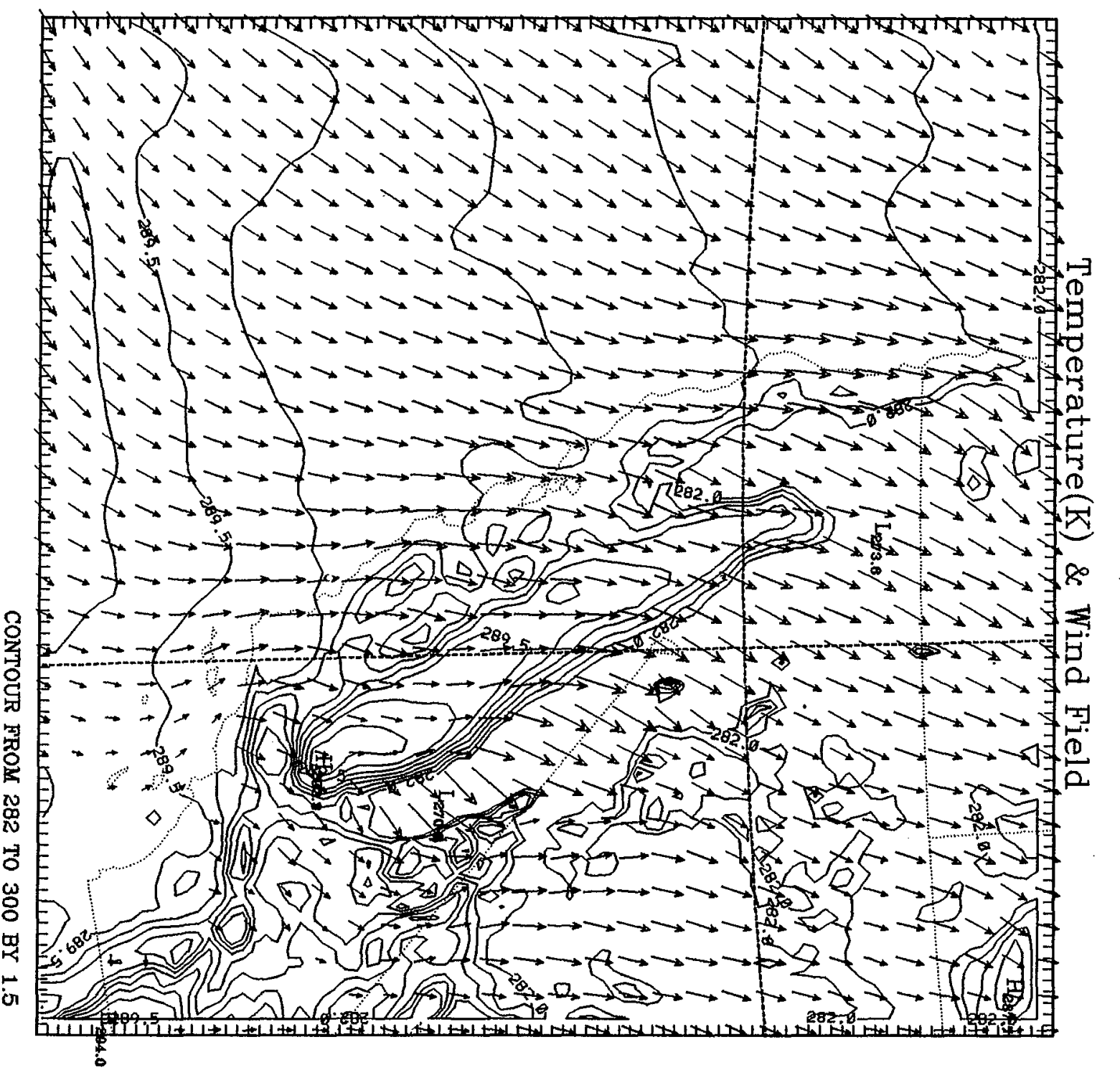




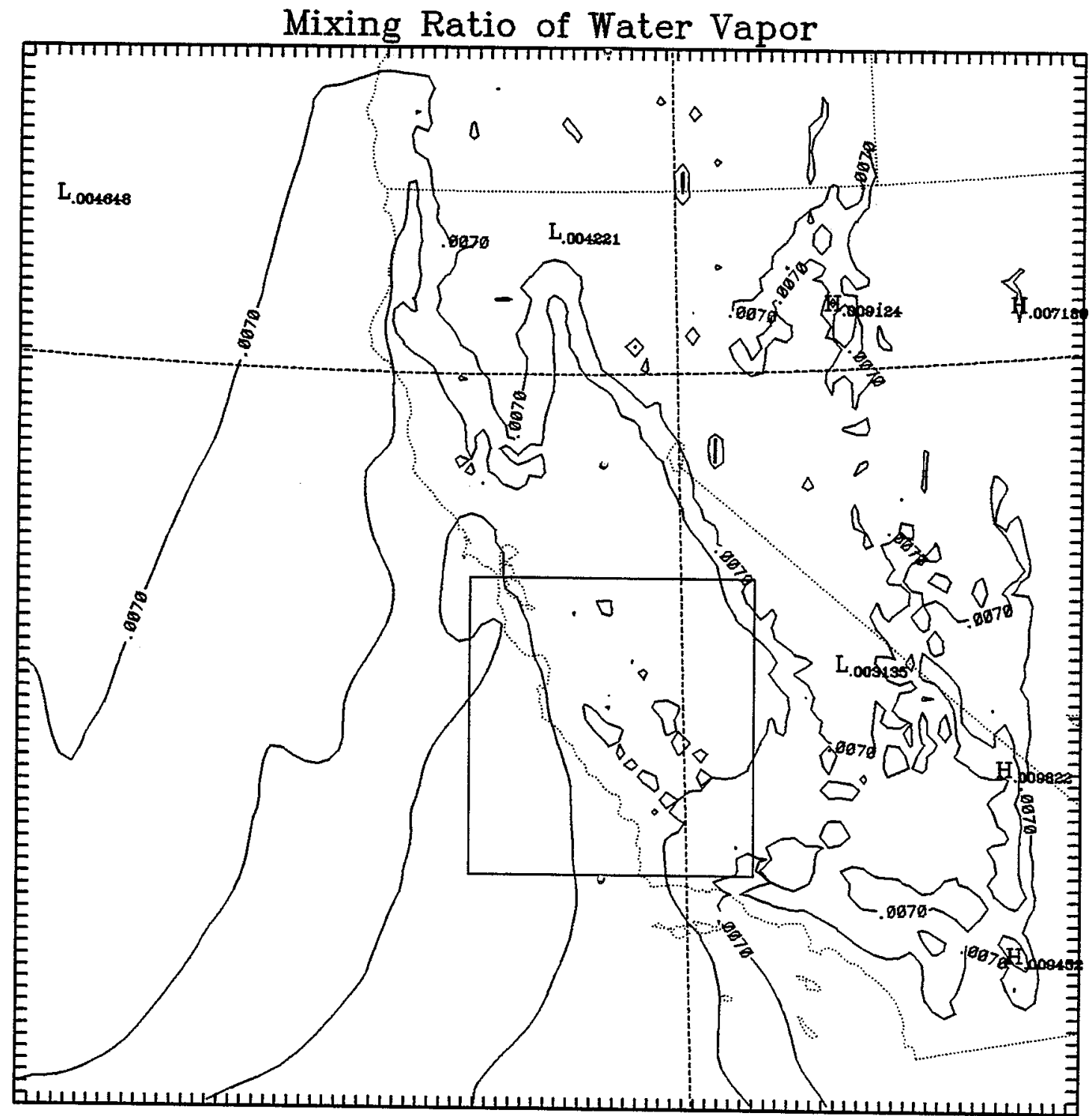

CONTOUR FROM .007 TO .019 BY .0015

Fig 10 


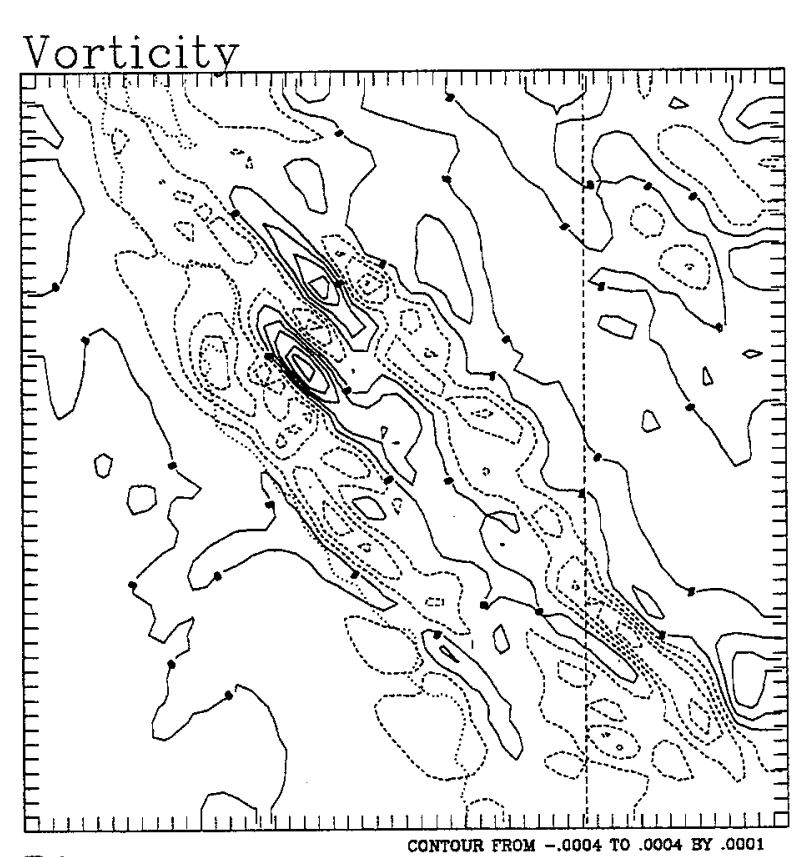

Divergence

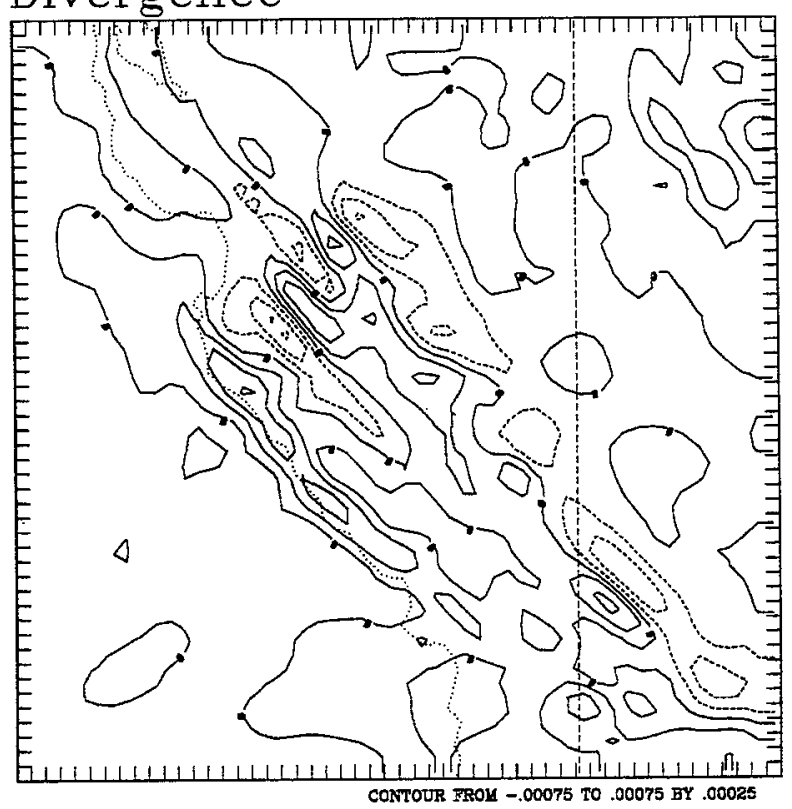

Precipitation

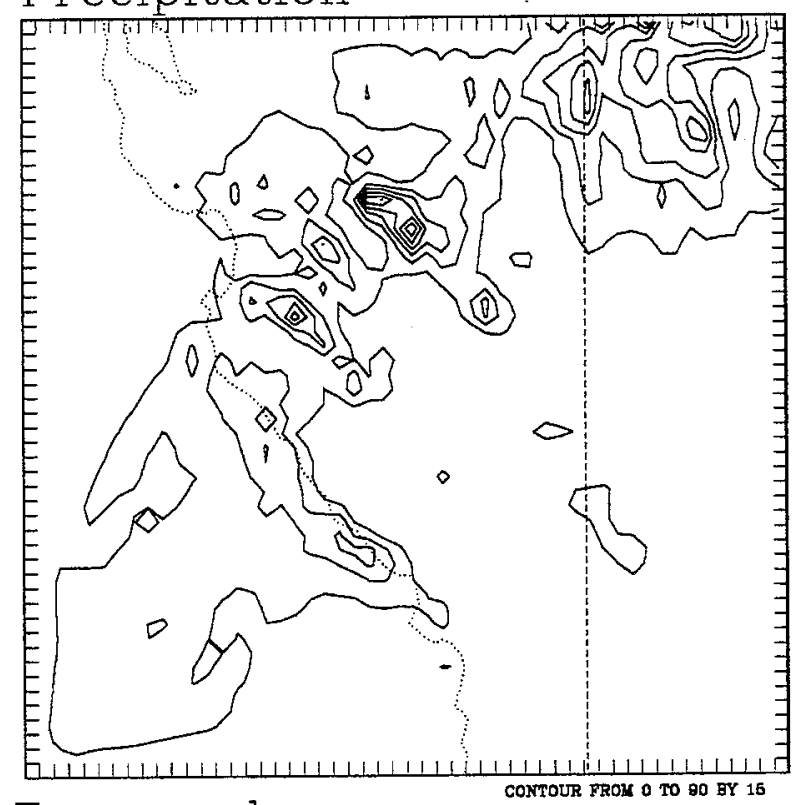

Topography

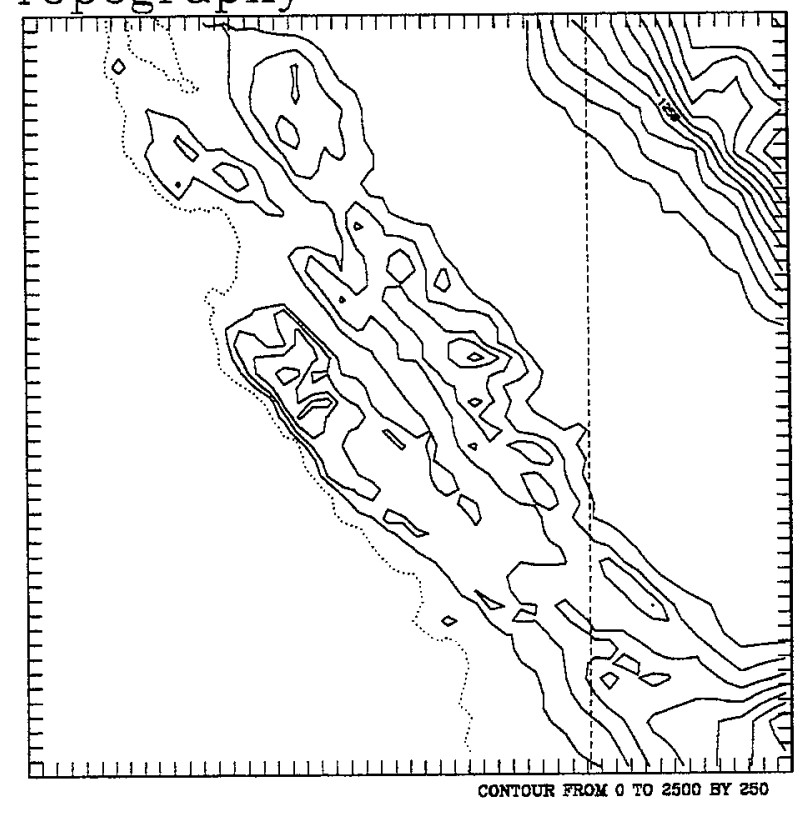




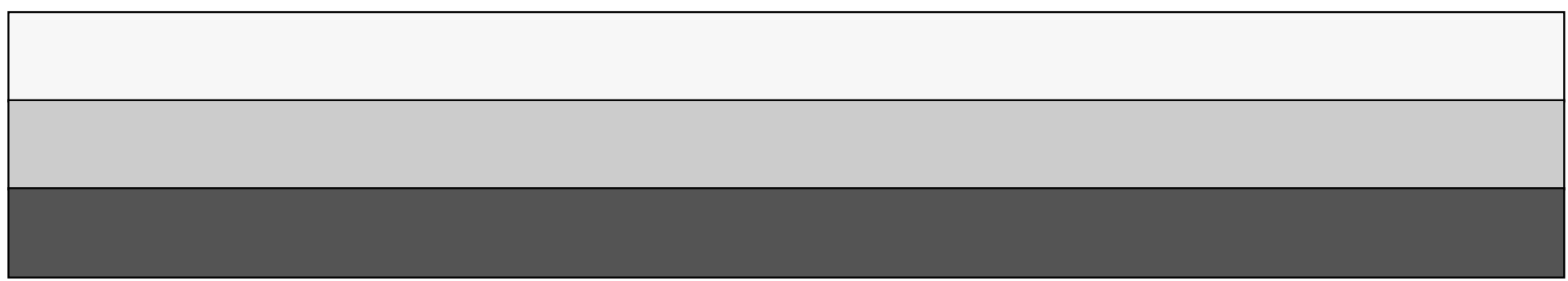

